\title{
Spatial and Temporal Distribution Characteristics of the humid index in North China Plain
}

\author{
LI Shuoyang ${ }^{1,2}$, YANG Guiyu ${ }^{2 *}$, DUAN Na ${ }^{3,2}$, WANG Lin ${ }^{2}$ \\ ${ }^{1}$ College of Water Conservancy and Civil Engineering, Inner Mongolia Agricultural University, Hohhot, 010018, China; ${ }^{2}$.The Institute of \\ Water Resource of China Institute of Water Resources and Hydropower Research, Beijing 100038,China; ${ }^{3}$ College of Water Conservancy \\ and Hydropower of Hebei University of Engineering, Handan 056021 China
}

\begin{abstract}
With the development of economy and society and the increase of population, water shortage and a series of water-related problems became universal problems. The north China plain has become a global focal point due to the poor water resource background and the impact of climate change and high-intensity human activity. Water circulation, as the carrier of water resource evolution, was affected by climate change through evapotranspiration and also reacts on the climate through energy change. The humid index, as an index of regional water and heat budget, can reflect the circulation characteristics of water supply and consumption. And it can also connect the water cycle and energy cycle organically. The comprehensive index which can comprehensively reflect the degree of surface moisture -- the surface humid index was adopted to reveal the relationship between water budget and climate change in north China plain. Based on the daily meteorological data of 82 meteorological stations in north China plain from 1960 to 2017, the evolution of wetting degree in the whole region was analyzed and the main influencing factors of the change were analyzed in combination with the main meteorological elements. The relevant research is of certain reference value for sustainable development of north China plain and coping with future climate change.
\end{abstract}

\section{Introduction}

Due to the high-intensity development and utilization of water resources by human beings, the original water cycle is affected or changed to a certain extent; water circulation, as a carrier of water resources evolution, is closely related to energy cycle through evapotranspiration. Therefore, the development and utilization of all forms of water resources are affected by the hydrological cycle and energy cycle, and also counteract the cyclic process. Under the influence of global climate change and highintensity human activities, the relationship of water cycle and energy cycle is more compact and complex, and has a certain impact on the sustainable development of countries and regions. According to the IPCC AR4th, the global average surface temperature increased by $0.74{ }^{\circ} \mathrm{C}$ from 1906 to $2005^{[1]}$, and the precipitation in the North China Plain showed a significant reduction trend ${ }^{[2]}$. The change of energy and natural incoming water directly led to the reduction of the amount of regional generalized water resources (full caliber); the increase in temperature accelerates the water cycle; and the change in surface temperature is affected by energy cycling factors such as solar radiation and surface reflection. Therefore, the evolution of water resources is affected by both water cycle and energy cycle, and the changes of them are the result of the combined effects of human activities and climate change.

As a measure of regional water and heat budget, the humid index can better reflect the dry and wet conditions of a region, that is, the characteristics of regional water consumption and consumption, and thus the relationship between water cycle and energy cycle can be reflected. The analysis of longer series of the wet index can reflect the evolution of climate and water resources under the combined effects of climate change and human activities. Therefore, in recent years, under the influence of climate change and high-intensity human activities, the research on the humid index has received extensive attention from scholars. Different focal points and problems from different spatial scales and time scales were analyzed and discussed in Qaidam Basin, Xinjiang, Northwest [3, 4], Yangtze River Delta [5], Sanjiangyuan and Qinghai [6, 7], Ankang ${ }^{[8]}$, Shaanxi ${ }^{[9]}$, Gansu Hedong Area ${ }^{[10]}$, Southwest China ${ }^{[11]}$ and the whole country ${ }^{[12-14]}$. Although the Wet Index has some conclusions in different regions and national large-scale scales, there are still some differences in the temporal and spatial changes of different regions and different time scales.

North China Plain is an important grain producing area in China, and there are abundant light and heat resources. The North China Plain is a strong and fine wheat production area in the country and the world and its output

"Corresponding author: E-mail address: guiyuy@iwhr.com 
of wheat accounts for about $50 \%$ of the country. The temperate monsoon climate in the North China Plain is mainly affected by the southeast monsoon. The annual precipitation is $500-900 \mathrm{~mm}$, showing a decreasing trend from the southeast to the northwest. The annual distribution of precipitation is uneven. The precipitation in summer can account for $50-75 \%$ of the whole year, about $80 \%$ concentrated on June to September. As the temperature rises in the spring, the evaporation increases, and the precipitation is less, the spring drought problem often occurs; with the winter wheat growth period (October- June in next year) and the water demand is misplaced, the North China plain becomes a typical supplementary irrigation area. Moreover, the region has a large population and a relatively developed economy, thus the demand for water resources is large. The impact of high-intensity human activities and climate change has triggered a series of problems such as ecological, environmental, groundwater over-exploitation and regional maximum temperature surges, which have become the focus in the world. In the paper, the surface wetting index was analyzed by using the meteorological data of 82 meteorological stations in the North China Plain from 1960 to 2017 as the carrier, reflecting the spatial and temporal distribution characteristics of the humid index over the past 58 years and its correlation with various climatic factors, which provides certain reference value for regional sustainable development, rational adjustment of planting structure, reduction of groundwater irrigation, and response to future climate change and protection of agro-ecological environment.

\section{Data collection}

The meteorological data covered in this paper were all from the China Meteorological Data Sharing Network (http://cdc.cma.gov.cn ). The data of the meteorological sites in the North China Plain and surrounding areas were screened, and 82 sites with strong representativeness and completence were selected. The specific site distribution and research area are shown in Figure 1. The data series are measured data from 1960 to 2017. Including measured data of daily precipitation, average temperature, average maximum temperature, average minimum temperature, air relative humidity, average wind speed, and sunshine hours.

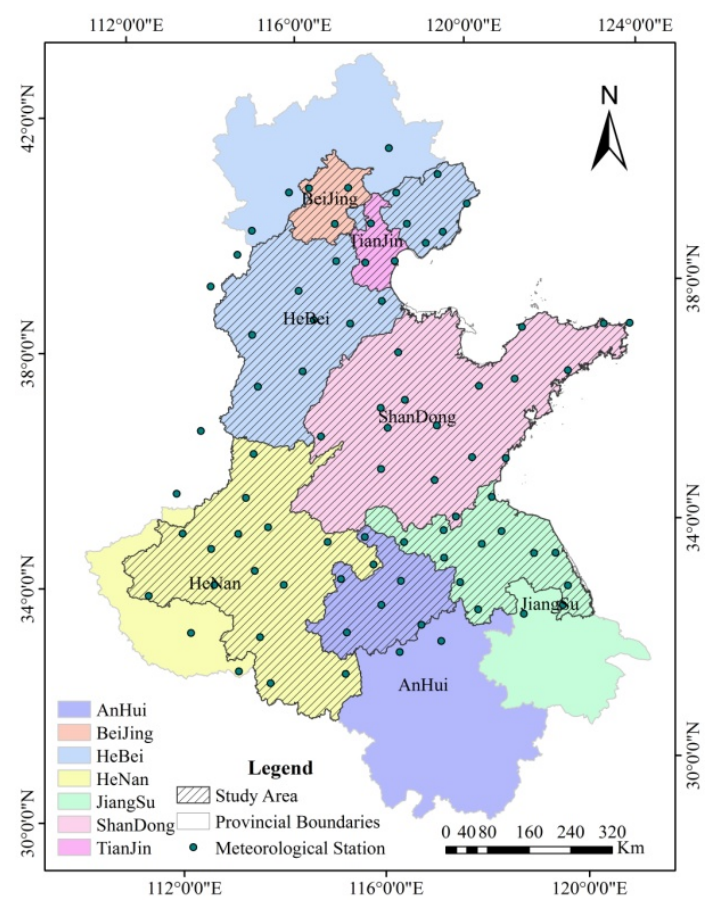

Fig1. Research area and the distribution of meteorological sites

\section{Methodology}

\subsection{Surface humid index}

In this paper, the ground precipitation $(\mathrm{P})$ and potential evaporation (ET0) are used to calculate the humid index $\mathrm{K}=\mathrm{P} / \mathrm{ET}$ 0. $\mathrm{P}$ is the measured precipitation of the weather station. The Penman-Monteith (PM) formula recommended by FAO in 1998 to calculate the ET0 of each station were used to calculate ET0 . The calculation formula is as follows:

ET0 $=\frac{0.408 \Delta\left(R_{n}-G\right)+\gamma \frac{900}{T+273} u_{2}\left(e_{s}-e_{a}\right)}{\Delta+\gamma\left(1+0.34 u_{2}\right)}$

Where: ET0 is the potential evaporation, $\mathrm{mm} / \mathrm{d} ; R_{n}$ is the net radiation on the surface of the crop, $\mathrm{MJ} /(\mathrm{m} 2 \cdot \mathrm{d})$; $G$ is the soil heat flux, $\mathrm{MJ} /(\mathrm{m} 2 \bullet \mathrm{d}) ; T$ is the Daily average temperature at 2 meters high, ${ }^{\circ} \mathrm{C} ; u_{2}$ is the wind speed at 2 meters high, $\mathrm{m} / \mathrm{s} ; e_{s}$ is saturated water vapor pressure, $\mathrm{kPa} ; e_{a}$ is the actual water vapor pressure, $\mathrm{kPa}$; $e_{s}-e_{a}$ is the saturated water vapor pressure difference, $\mathrm{kPa} ; \Delta$ is the inclination of the pressure curve; $\gamma$ is the hygrometer constant, $\mathrm{kPa} /{ }^{\circ} \mathrm{C}$;

\subsection{Mann-Kendall trend test}

For the hydrological sequence $x_{i}$, first determine all the dual values $\left(x_{i}, x_{j} ; j>i, i=1,2, \ldots, n-1 ; j=i+1, i+\right.$ $2, \ldots, n)$, The number of occurrences of $x_{i}<x_{j}$ is p. For a sequence without trend, the mathematical expectation of $\mathrm{p}$ is:

$$
E(p)=\frac{1}{4} n(n-1)
$$

Construct statistics for the Mann-Kendall rank correlation test: 


$$
U=\frac{\tau}{[\operatorname{Var}(\tau)]^{1 / 2}}
$$

Where: $\tau=\frac{4 p}{n(n-1)}-1, \operatorname{Var}(\tau)=\frac{2(2 n+5)}{9 n(n-1)}, n$ is the number of sequence samples 。

As $n$ increases, $U$ quickly converges to a normalized normal distribution.

Assuming that there is no trend in the sequence, when a significant level $\alpha$ is given, the critical value $U_{\alpha / 2}$ can $U_{\alpha / 2}$, the hypothesis is rejected, ie, the trend of the sequence is significant. The statistic $U$ can also be used as a measure of the trend size of the hydrological sequence. The larger the $|U|$, the more significant the trend change of the sequence can be explained.

\subsection{Empirical Orthogonal Function}

The Empirical Orthogonal Function (EOF) decomposition is also called principal component analysis in multivariate statistical analysis. EOF was first proposed by statistician Pearson in 1902, and it was quoted in the climate field in the early 1970s. Spatial distribution in the meteorological field is often detected by many monitoring points, which makes it difficult to study the characteristics of temporal and spatial distribution changes directly ${ }^{[15]}$. The EOF analysis describes the original meteorological variable field using a few spatial distribution modes, and basically covers the information of the original variable field. Usually expressed in terms of the contribution rate of the vector field. The advantage is that EOF has no fixed function, can decompose randomly distributed sites in a limited area, and easily concentrates the information of the be found in the normal distribution table, and when $|U|>$

variable field on several distribution modes, and the separated variable fields have physical meaning.

Combine monitoring points and detection time into a matrix for the study area $X=\left[\begin{array}{ccc}a_{11} & \cdots & a_{1 n} \\ \vdots & \ddots & \vdots \\ a_{h 1} & \cdots & a_{h n}\end{array}\right]$, Each row represents a different monitoring point, each column represents a different detection time, the matrix $\mathrm{X}$ is normalized and its coordination matrix $\mathrm{Y}$ is sought:

$$
Y=X^{t} \times X
$$

Using the formula its covariance matrix $\mathrm{Y}$ find eigenvalues and eigenvectors, where eigenvalues of the covariance matrix of the diagonal matrix $\mathrm{Y}$ is included in matrix A, B is the matrix of eigenvectors corresponding to the eigenvalues of the matrix Y.

$$
Y B=B A
$$

For each eigenvalue in the matrix $A$, there is a corresponding eigenvector. These eigenvectors are the empirical orthogonal functions that are decomposed and are drawn to different spatial distribution modalities according to the coordinates of the monitoring station. Where the contribution rate of the $i$ eigenvector is $\frac{\lambda_{i}}{\sum \lambda}$, where $\lambda_{i}$ is the ith eigenvalue and $\sum \lambda$ is the sum of all eigenvalues.

\section{Result analysis}

\subsection{Spatial distribution of dryness and wetness}
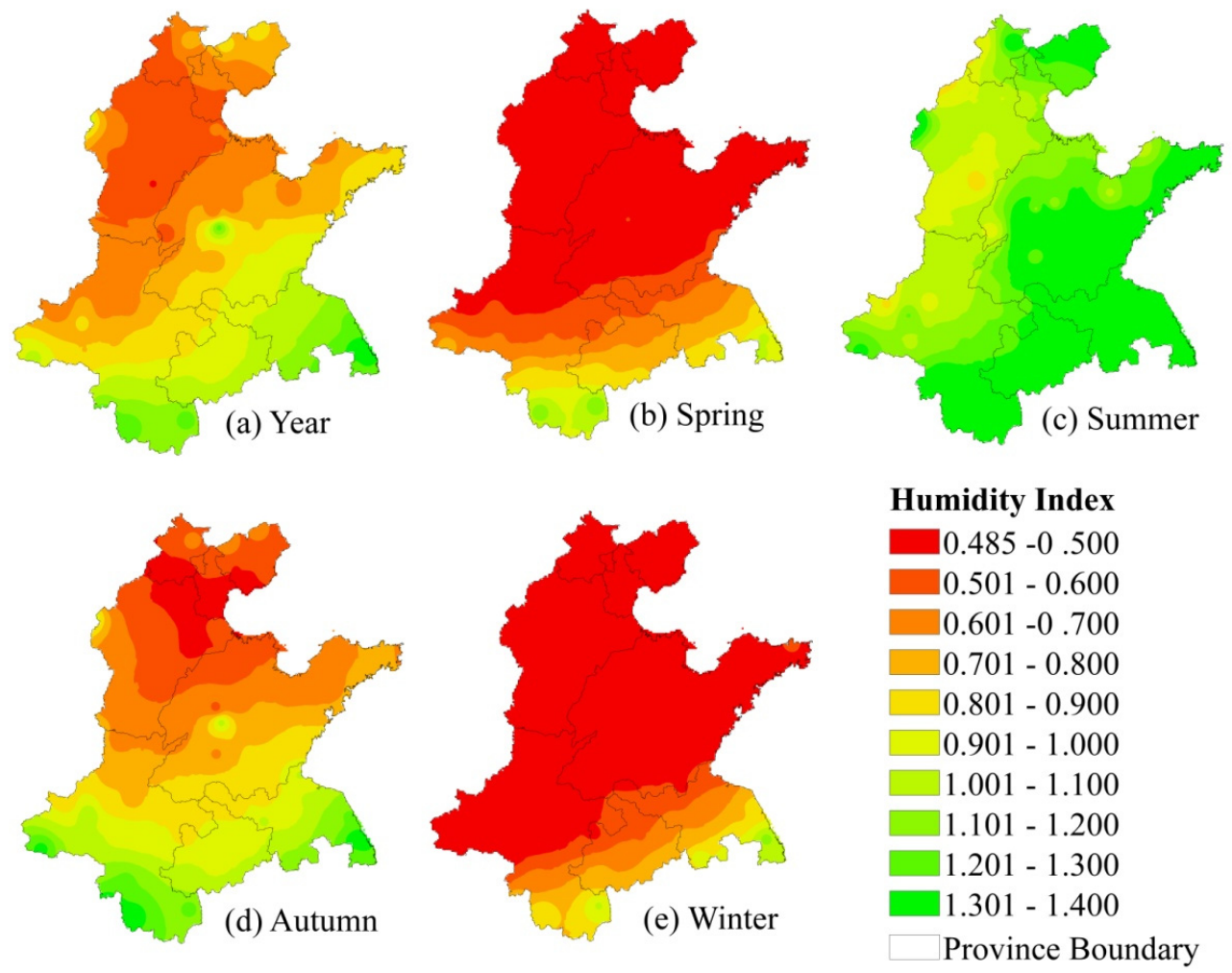

Fig2. The distribution of humid index

The average surface humid index of each site in the study 
significant. The overall performance is the regional boundary line from the central part of Henan Province to the southwest and northeast of Shandong Province, showing a decreasing trend from southeast to northwest(Fig2.a). The low value area (around 0.5) is mainly located in the northwest, and the high value area (around 1.3) is located in the south and southeast. The difference between the north and the south is about 0.8 , and the difference between the north and the south is obvious. The humid index in most areas in the south is above 1.0 , while in the north is mainly around 0.6 .

The spatial distribution of the annual average humid index is a superposition of the spatial distribution characteristics of the four-season humid index. The distribution of the seasonal distribution and the annual average humid index are somewhat similar, but there are some differences between the seasonal and annual average humid indices spatially and numerically. The humid index of the whole region is less than 0.5 in the north, and between 0.6-1.3 in the south, and is increasing to the south, with the boundary between the central and southern parts of Henan Province and the southern part of Shandong Province in spring and winter. However, compared with spring, the north-south humid index boundary line moves southward in winter, located in the south of Shandong Province and southern Henan Province. In summer, the humid index of most regions in the North China Plain is above 0.9. Although the humid index of spatial

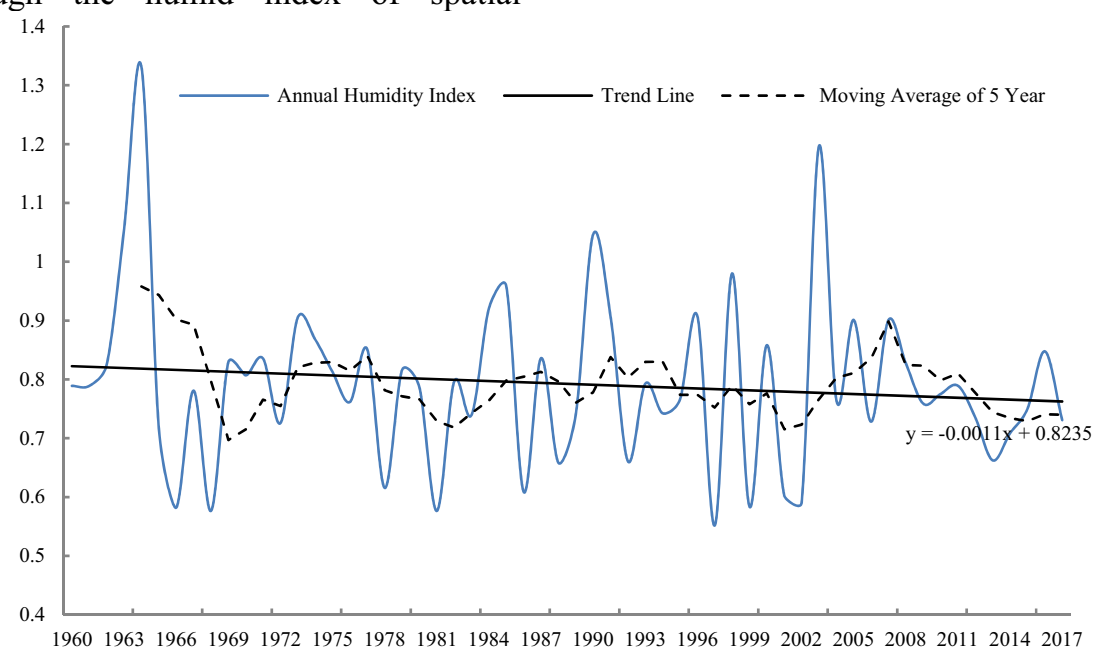

Fig3. The change of annual average humid index of the North China Plain from $1960-2017$

It can be seen from Figure 3 that the annual average humid index of the North China Plain fluctuates between 0.5 and 1.35 . The multi-year average is 0.79 , the maximum value appeared in 1964, and the minimum value appeared in 1997. The maximum and minimum values differ by about 0.7 .In the past 58 years, the humid index has generally decreased by $0.011 / 10 \mathrm{a}$. The humid index of the North China Plain in the 1960s, $1970 \mathrm{~s}, 1990 \mathrm{~s}$, and 2000-2009 is a little large, which is $4.42 \%, 0.92 \%, 0.19 \%$, and $2.58 \%$, relative to the multi-year average, respectively; They were $3.82 \%$ and $5.37 \%$ smaller than the average, respectively in $80 \mathrm{~s}$ and 2010-2017. distribution shows higher than the northwestern region, the difference between the two is small, about 0.2. The change of humid index in autumn is between winter, spring and summer, and the difference between regions is obvious. The overall humid index in south is larger than that in the north, with the most parts of Beijing, Tianjin and Hebei Province the smallest, less than 0.5, the humid index of southern Hebei, northern Shandong and northern Henan is $0.6-0.8$, which is greater than 0.8 in southern Henan, southern Shandong and south of it.

\subsection{Interannual variation of dryness and wetness}

The inverse distance weight (IDW) interpolation method is one of the spatial interpolation methods. With the ability to comprehensively reflect the contribution of the distance between the interpolation point and the sample point to the interpolation point. The closer the sample point is, the larger the weight given by the sample point is, and the weight is given. Contribution is inversely proportional to distance. Therefore, in the paper, IDW interpolation method were used to spatially interpolate the monthly humid index of 82 sites in Arcgis 10.2 to obtain the monthly average humid index of the North China Plain. The interannual evolution characteristics of the humid index of the whole study area were analyzed based on above.
The humid index in spring, summer and autumn showed a decreasing trend, and the change tendency rate was $0.99 / 10 \mathrm{a}, 0.015 / 10 \mathrm{a}$ and $0.018 / 10 \mathrm{a}$, respectively. The humid index in winter showed an increasing trend, and the change tendency was increased by $0.041 / 10 \mathrm{a}$. The average annual humid index of each season was $0.43,1.23,0.78$ and 0.37 , respectively. The humid index of the four seasons was different during the year, with the largest in summer, about three timescompared to that of spring and winter. 

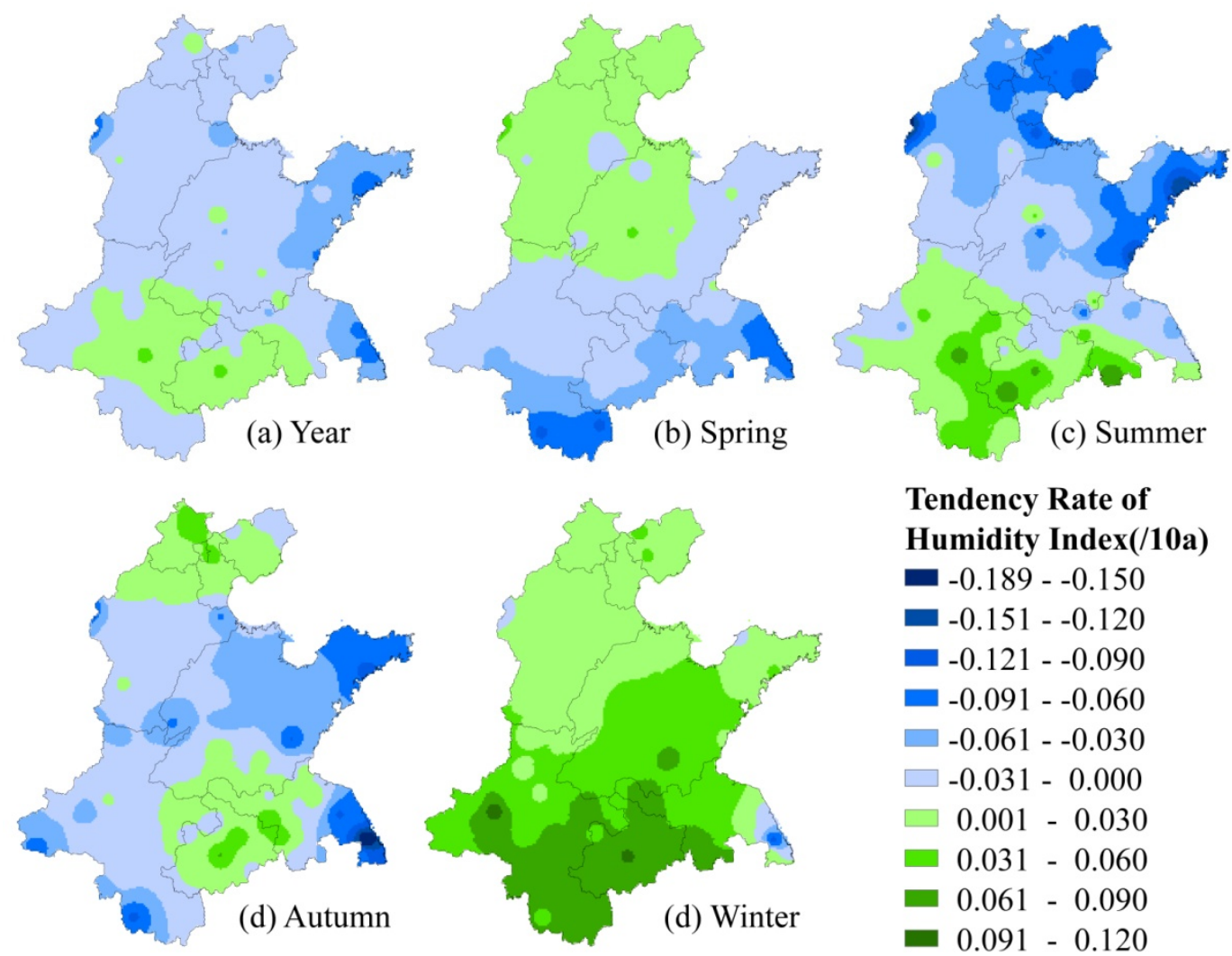

Fig4. The distribution of humid index of spatial change tendency rate

In order to analyze the differences in the inter-annual variation of the humid index, the propensity rate of the 58year humid index of 82 stations was calculated and the spatial change propensity rate distribution map was plotted, as shown in Fig. 4. The annual average wett index of the North China Plain showed a decreasing trend from 1960 to 2017 , that is, the climate drying trend, the rate of change was around 0 to $0.03 / 10 \mathrm{a}$, and the humid index of the Shandong Peninsula and the northeastern part of Jiangsu decreased More, about $-0.06 / 10 \mathrm{a}$ or so. In the central and eastern parts of Henan Province and the northern part of Anhui Province, the humid index increased slightly, and the rate of change was about $0.03 / 10 a$.

In the spring, the humid index of Hebei, Tianjin, Beijing and the northwestern part of Shandong Province was increased, about $0-0.03 / 10 \mathrm{a}$. The southern part of Henan, Jiangsu, Anhui and other regions showed a decreasing trend, about $-0.06 / 10 \mathrm{a}$. In the summer, the northeast showed a decreasing trend, and the southwest showed an increasing trend. In the autumn, the humid index in the northern part of Anhui, northwestern Jiangsu, eastern Henan and southern Shandong, and around Beijing showed an increasing trend, the rate of change ranged from 0 to $-0.06 / 10 \mathrm{a}$, and other areas showed a decreasing trend. Among which, the degree of reduction in the northeastern part of Jiangsu and east part of Shandong is large, and the rate of change is about $-0.09 / 10 \mathrm{a}$. In the winter, the humid index of the whole region showed an increasing trend, and the increase increased from north to south. The change rate of the humid index in Hebei was small between $0-0.03 / 10 \mathrm{a}$. The humid index of Henan, Shandong, Anhui and northern Jiangsu increased. The rate is between 0.06-0.09/10a. Combined with the changes in spring, the reason is that the soil moisture in winter is relatively good. As the temperature rises in spring (the temperature of climate change increases), the increase in evaporation causes the wetness index to decrease.

\subsection{Spatial distribution modal analysis of humid index}

The spatial and temporal distribution of annual average humid index (K value) includes time and space variables. In terms of time, if the interpolation calculation is carried out every year, there will be $\mathrm{n}$ spatial distributions, which mean that the time variable has $\mathrm{n}$ indicators. However, the indicators of different time variables and different spatial variables are correlated, which makes the information reflected by $\mathrm{K}$ value overlapped to some extent. Empirical orthogonal function (EOF) is to recombine multiple research indexes of different research variables into new mutually independent comprehensive indexes to replace the original indexes. which called healthy latitude thought.

The 58 years' humid index of 82 sites was interpolated in space year by year, thus reaching 58 kinds of spatial distribution form from 1960 to 2017. And the empirical orthogonal function method was used to analyze the spatial characteristics of humid index in north China. Five spatial distribution forms were extracted according to the probability statistics. The original 58 spatial distributions were represented by five spatial distributions. The complex spatial situation was simplified to reveal the spatial distribution of humid degree clearly. The results show (Tab 1): the cumulative contribution rate of the first eight feature vectors of the average annual humid index 
(K value) in the north China plain from 1960 to 2017 is $75.69 \%$. The cumulative contribution rate of the first five feature vectors is close to $70 \%$, and the first five feature vectors can better represent the spatial variation features of the annual average moist index $\mathrm{K}$ value of the north China plain. The contribution rates of the first and second eigenvectors are all greater than $10 \%$. The spatial distribution representation is relatively high. Therefore, the first two eigenvectors are emphatically analyzed.
Tab 1 Contribution rate and cumulative contribution rate of the first 8 characteristic vectors of humid index in north China

\begin{tabular}{ccccccccc}
\multicolumn{10}{c}{ plain } \\
\hline Eigenvectors & First & $\begin{array}{c}\text { Seco } \\
\text { nd }\end{array}$ & Third & $\begin{array}{l}\text { Fourt } \\
\text { h }\end{array}$ & Fifth & Sixth & $\begin{array}{l}\text { Seve } \\
\text { nth }\end{array}$ & $\begin{array}{c}\text { eight } \\
\text { h }\end{array}$ \\
\hline Eigenvalues & 1.33 & 0.62 & 0.28 & 0.24 & 0.15 & 0.13 & 0.09 & 0.08 \\
Contribution & 34.33 & $\begin{array}{c}16.08 \\
\%\end{array}$ & $\begin{array}{c}7.25 \\
\%\end{array}$ & $\begin{array}{c}6.24 \\
\%\end{array}$ & $\begin{array}{c}3.94 \\
\%\end{array}$ & $\begin{array}{c}3.29 \\
\%\end{array}$ & $\begin{array}{c}2.42 \\
\%\end{array}$ & $\begin{array}{c}2.13 \\
\%\end{array}$ \\
$\begin{array}{c}\text { Rate(\%) } \\
\text { Cumulative }\end{array}$ & $\begin{array}{c}34.33 \\
\%\end{array}$ & $\begin{array}{c}50.41 \\
\%\end{array}$ & $\begin{array}{c}57.67 \\
\%\end{array}$ & $\begin{array}{c}63.90 \\
\%\end{array}$ & $\begin{array}{c}67.85 \\
\%\end{array}$ & $\begin{array}{c}71.14 \\
\%\end{array}$ & $\begin{array}{c}73.56 \\
\%\end{array}$ & $\begin{array}{c}75.69 \\
\%\end{array}$ \\
Contribution(\%) & $\begin{array}{c}\% \\
0\end{array}$
\end{tabular}
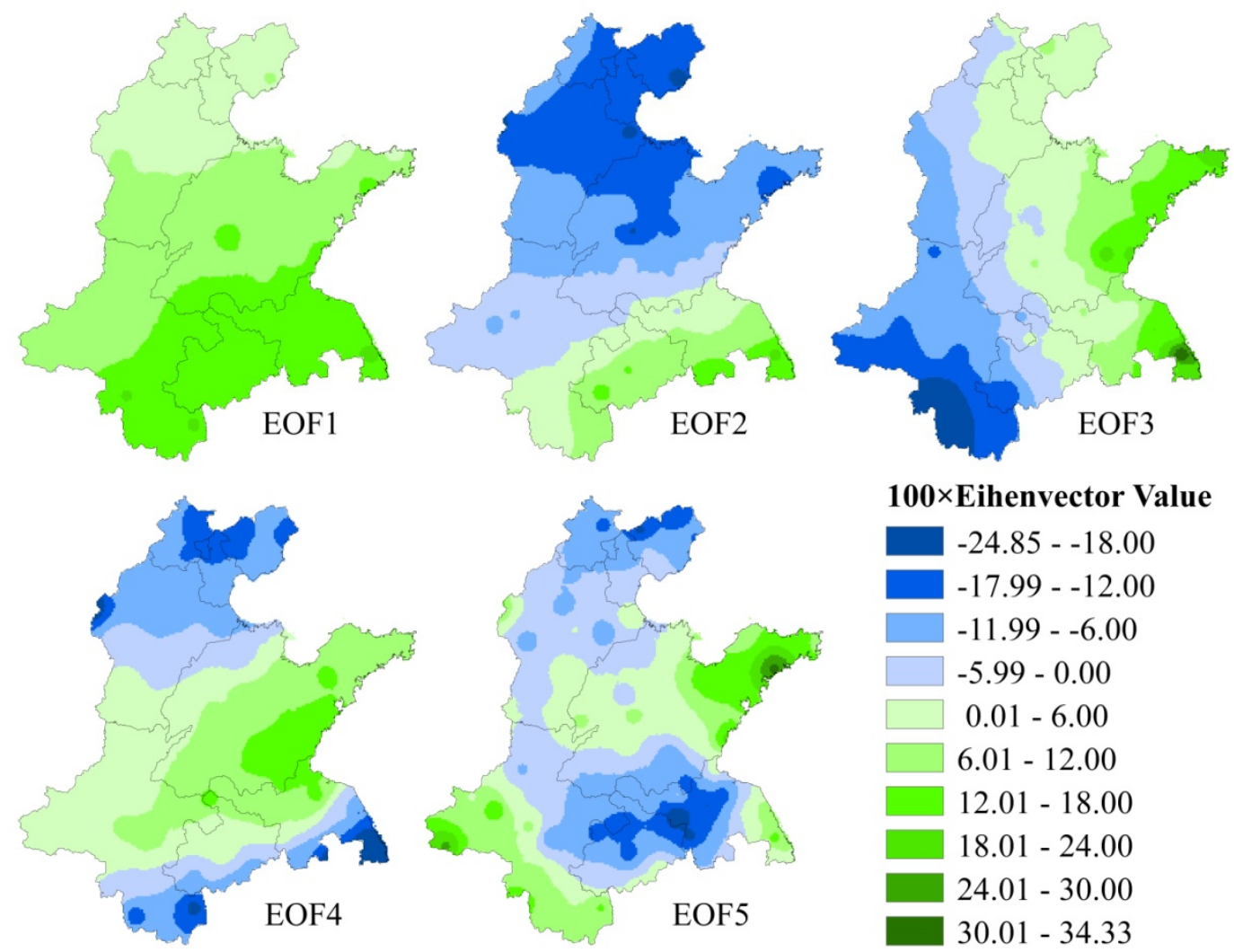

Fig5 EOF analysis of annual average humid index in north China plain

The first eigenvector (EOF1) is positive, with a contribution rate of $34.33 \%$ and value range between 0 and 0.18 (marked as eigenvector value multiplied by 100 in the figure).It indicates that the spatial distribution of the humid index presents the same form in the north China plain. The whole region is relatively dry or humid. But the eigenvectors appear to be more south than north in numerical terms. It means that the south is drier or wetter than the north. The value range of the second feature vector (EOF2) is $-0.24-0.30$. The contribution rate is $16.08 \%$. In terms of spatial distribution, there is a demarcation line that runs northeast across south-central Shandong province and Henan province, which divides the study area into north negative region and south positive region.It reflects the dry and wet conditions in the north and south of the north China plain in opposite forms. Which means the north is dry and the south is wet or the north is wet and the south is dry.

\section{Discussion and Conclusion}

\subsection{Discussion}

In terms of spatial distribution, the humid index is smaller in the north than south. In the annual change, there is a trend of drying. It is similar to the research results of many Chinese experts and scholars in different spatial scales ${ }^{[12,}$ 13, ${ }^{16-20]}$.However, humid index is a composite index affected by various meteorological factors. In order to reveal the main influencing factors of humid index change in north China, further analysis was made based on precipitation, temperature, relative humidity, wind speed and sunshine time in north China plain. The results show (Tab 2): with the global climate change, the climate of north China plain has also changed in recent 58 years. But in a multi-year average scale, the humid index was positively correlated with precipitation, relative humidity and temperature, and negatively correlated with wind speed and solar radiation. From large to small, the correlation is precipitation, relative humidity, temperature and solar radiation. Among which, precipitation is the 
leading factor of the change of humid index, and its overall change law is similar to the spatial distribution of precipitation ${ }^{[21]}$. The correlation coefficient of both is 0.889.Secondly, relative humidity; wind speed and solar radiation are relatively small.

In season, the change of spring humid index is mainly affected by precipitation, relative humidity and solar radiation. The effect of solar radiation on the solar radiation is higher than the annual average. The summer humid index is affected by meteorological factors, the influence from high to low were precipitation, relative humidity, solar radiation, temperature and wind speed in sequence. The humid index in autumn is the influence of precipitation, temperature, relative humidity and solar radiation. The temperature is low in winter and the effect on humid index is not significant. The comprehensive analysis shows that the variation of humid index in north China plain is mainly affected by precipitation, relative humidity and solar radiation.

Tab2 Correlation coefficient of humid index and influencing factors in north China from 1960 to 2017

\begin{tabular}{|c|c|c|c|c|c|}
\hline & $\begin{array}{l}\text { Precipi } \\
\text { tation }\end{array}$ & $\begin{array}{l}\text { Tempe } \\
\text { rature }\end{array}$ & $\begin{array}{l}\text { Wind } \\
\text { Speed }\end{array}$ & $\begin{array}{l}\text { Relative } \\
\text { Humidity }\end{array}$ & $\begin{array}{c}\text { Solar } \\
\text { Duratio } \\
\mathrm{n}\end{array}$ \\
\hline Year & $0.889^{* *}$ & $0.549^{* *}$ & $\underset{*}{-}+{ }_{*}^{-}$ & $0.838^{* *}$ & $-0.251^{* *}$ \\
\hline $\begin{array}{l}\text { Spri } \\
\text { ng }\end{array}$ & $0.864^{* *}$ & 0.081 & -0.081 & $0.767^{* *}$ & $-0.528^{* *}$ \\
\hline $\begin{array}{c}\text { Sum } \\
\text { mer }\end{array}$ & $0.980^{* *}$ & $0.426^{* *}$ & $\begin{array}{c}- \\
0.384^{*}\end{array}$ & $0.833^{* *}$ & $-0.576^{* *}$ \\
\hline $\begin{array}{l}\text { Aut } \\
\text { umn }\end{array}$ & $0.845^{* *}$ & $0.209^{* *}$ & -0.013 & $0.789^{* *}$ & $-0.582^{* *}$ \\
\hline $\begin{array}{l}\text { Wint } \\
\text { er }\end{array}$ & $0.975^{* *}$ & 0.047 & $\begin{array}{c}- \\
0.238^{*} \\
*\end{array}$ & $0.669^{* *}$ & $-0.652^{* *}$ \\
\hline
\end{tabular}

** Means that the confidence test of 0.01 has been passed

In space, under the average condition of nearly 58 years, precipitation in north China gradually increases from south to north. Climatic factors such as precipitation, relative humidity and sunshine duration are all affected by geographical location, climatic conditions and southeast monsoon, which together result in spatial differentiation of humid index.

In this change of moisture index, due to the decreasing trend of precipitation ${ }^{[21]}$, the amount of water available for natural precipitation for evaporation is limited, and irrigation water also plays a certain role. According to the analysis of irrigation system in plain areas, in spring, the humid index in Hebei, Beijing, Tianjin and northwestern Shandong increased.

The increase in wetting index may be related to irrigation. In spring, winter wheat returns to green, and winter and spring precipitation is less, which cannot meet the moisture required for wheat growth. Winter irrigation and spring irrigation may increase air humidity, resulting in a positive correlation and significant correlation between humidity index and relative humidity. In winter, due to the decrease of precipitation and temperature, solar radiation is another leading factor in the wetting index.

\subsection{Conclusion}

Through calculation of the humid index in north China and analysis of its spatio-temporal evolution characteristics by various methods, the following conclusions are drawn:

(1) Perennial average humid index is between 0.485 and 1.4. Affected by factors such as precipitation, topography and climatic conditions, the spatial difference is relatively large, which generally shows a tendency of drying from southeast to northwest. The annual average humid index is the superposition of the spatial distribution characteristics of the four seasons humid index. The spatial distribution rules of each season are somewhat similar to humid index of annual scales to some extent. However, the four seasons and the annual average humid index differ from each other in spatial distribution and humid index values.

(2) From 1960 to 2017, there was a trend of drought in the north China plain. The humid index in spring, summer and autumn declined, while that in winter was increased. The spatial distribution of wetting index is obtained by EOF analysis. The spatial distribution of the first eigenvector presents the same result of region drying or wetness. The spatial distribution of the second eigenvector reflects that the dry (or wet) conditions in the north and south of the north China plain are in opposite form.

(3) Humid index is a comprehensive index affected by many factors. Humid index is positively correlated with precipitation, temperature and relative humidity, and negatively correlated with wind speed and sunshine time. Different seasons and different factors have different effects on the humid index. Precipitation, relative humidity and sunshine time in spring are significantly correlated with the humid index. In summer, all factors have significant influence on the humid index. Precipitation, temperature, relative humidity and sunshine time have significant influence on autumn humid index. Changes in the humid index are linked to global climate change and to the impact of human activity.

\section{Acknowledgment}

This study was funded by research on the supporting capacity of water resources to regional social and economic development (2015-ZD-16-02-03).

\section{Reference}

1. Contribution of Working Group I to the Fourth Assessment Report of the Intergovern-mental Panel on Contribution of Working Group I to the Fourth Assessment Report of the Intergovern-mental Panel on [Z]. 2007.

2. Duo A, Wenji Zhao, Zhaoning Gong, et al. Temporal analysis of climate change and its relationship with vegetation cover on the north china plain from1981 to 2013 [J],Acta Ecologica Sinica, 2017(02):576-592.

3. Liya Jin, JIng Li, Xin Wang, et al. The temporal and spatial distribution of Turface Dry-Wet Conditions over Northwestern China in recent 50 years [J]. Journal of Geographical Sciences, 2004(06):847-854.

4. Xiaoyan Huang, Mingjun Zhang, Wenxiong Jia, et al. 
Variations of surface humidity and its influential factors in Northwest China [J]. Advances in Water Science, 2011(02):151-159.

5. Yu Xu, Yanfei W, Gang Xu, et al. Characteristics of Surface Humidity and Extreme Drought/Wet Events in Yangtze River Delta [J]. Journal of Natural Resources, 2017(09):1579-1590.

6. Zhiping Zhao, Xiao Guan, Guo Li, et al. Trend analysis of climatic change in the Three River Headwater Region in Qinghai Province during last 45 years [J]. Journal of Arid Land Resources and Environment, 2017(04):148-153.

7. Dekun Liu, Junbang Wang, Shuhua Qi. Analysis on Dry Trend Based on Moisture Index in Qinghai Province in the Recent 35 Years [J]. Research of Soil and Water Conservation, 2014(02):246-250.

8. Yufeng Liu, Zhihua Yuan, Lin Wu, et al. Analysis of dry-wet condition and its cycles in Ankang of Shaanxi Province in recent 55 years based on surface humidity index [J]. Journal of Natural Disasters, 2016(03):1121.

9. Yufeng Liu, Zhihua Yuan, Jianmin Feng, et al. Drywet condition of Shaanxi Province in recent 56 years based on surface humidity index $[\mathrm{J}]$. Arid Land Geography, 2016(06):1186-1196.

10. Yifei Zhao, Bo Zhang, Duoyiong Zhang, et al. Surface humidity index and the impacting climatic factors in Hedong region of Gansu province[J]. Progress in Geography, 2013(01):95-104.

11. Yun Wang, Puxing Liu, Liguo Cao, et al. Characteristics of Southwestern China Dry-wet Condition Based on Wetness Index in 1960-2011[J], Journal of Natural Resources, 2014(05):830-838.

12. Qi Hu, Bei Dong, Xuebiao Pan, et al. Spatiotemporal variation and causes analysis of dry-wet climate over period of 1961-2014 in China[J]. Transactions of the Chinese Society of Agricultural Engineering, 2017(06):124-132.

13. Chang Liu, Spatiotemporal variations of aridity in China during 1961-2015 [D]. Lanzhou University, 2017.

14. Shuanghe Shen, Fangmin Zhang, Qiong Sheng. Spatio-temporal changes of wetness index in China from 1975 to 2004 [J]. Transactions of the Chinese Society of Agricultural Engineering, 2009(01):11-15.

15. Fengying Wei. Modern climatic statistical diagnosis and prediction techniques[M]. Beijing: China Meteorological Press, 2007.

16. Wen Wang, Jinting Wang. Variation trend of surface humid index in China from 1951 to 2009 [ J ] . Journal of Meteorology and Environment, 2011(05):1-6.

17. Ling Wang, Xianqun Xie, Yunsheng Li, et al. Changes of humid index and borderline of wet and dry climate zone in northern China over the past 40 years [J]. Geographical Research, 2004(01):45-54.

18. Zhuguo Ma, Congbin Fu. Trend of Surface Humid Index in the Arid Area of Northern China [J]. Acta Meteorologica Sinica, 2001(06):737-746.
19. Hongli Zhang, Qiang Zhang, Qian Liu, et al. The temporal and spatial distribution characteristics of dryness index and its main factor in China [J]. Journal of Lanzhou University(Natural Sciences), 2016(04):484-491.

20. Fangmin Zhang, Shuanghe Shen. A Study on Dry/Wet Conditions and Changes of Dry/Wet Climate Boundary in China [J]. Transactions of Atmospheric Sciences, 2008(04):574-579.

21. Lan Fan, Changhe Lv, Biao Yang, et al. Long-term trends of precipitation in the North China Plain[J]. Journal of Geographical Sciences, 2012(06):9891001. 